\title{
Berlim: fronteiras imaginárias, fronteiras reais?
}

\author{
BARBARAFREITAG
}

\begin{abstract}
Berlim nas manchetes:
09.10.89: Cai o Muro de Berlim.

01.07.90: Unificação monetária: RDA e Berlim oriental subordinam-se ao império da Deutsche Mark!

03.10.90: Reunificação alemã. Reunificação de Berlim. 12.07.94: "Berlin is free now", says Clinton.

Berlim despede-se das tropas americanas, inglesas, francesas e russas "de ocupação".
\end{abstract}

Berlim é uma cidade livre e reunificada: jurídica e politicamente.

RESUMO: Neste artigo, a autora procura recuperar através dos romances de Theodor Fontane (1819-1898), Alfred Döblin (1878-1957) e Irina Liebmann (1943) as imagens urbanas de três períodos decisivos da história e vida de Berlim: os Gründerjahre (anos de fundação) a partir de 1870, o período da "República de Weimar" do entre-guerras e, finalmente, o período do Muro de Berlim e seu desmoronamento em 1989. Indaga-se, a partir desta "memória literária", quais as perspectivas da cidade futura.

m minha exposição sobre Berlim, eu poderia seguir o roteiro sugerido por Rolf Lindner (1990), descobrindo a "cultura urbana" de Berlim pelas manchetes de jornais, reportagens de rádio e televisão ou nos filmes antigos e recentes realizados em Berlim ${ }^{1}$, entre os quais, Berlin Alexanderplatz ${ }^{2}$.

Propus-me, contudo, reelaborar a "memória" da cidade de Berlim através de alguns textos literários do passado e presente, privilegiando três gerações de escritores:
UNITERMOS:

Imaginário,

fronteiras reais, fronteiras imaginárias, Berlim,

queda do muro.

Texto re-elaborado de duas palestras sobre Berlim, apresentadas no SIMPÓSIO UERJ: "Memória, Cidade, Cultura", realizado no Rio de Janeiro entre 23 e 25 de agosto de 1994.

Professora da Universidade de Brasília 
FREITAG, Barbara. Berlim: fronteiras imaginárias, fronteiras reais? Tempo Social; Rev. Sociol. USP, S. Paulo, 6(1-2): 127-145, 1994 (editado em jun. 1995).

- Theodor Fontane $(1993,1979)^{3}$, retratando os Gründerjahre, da Berlim capital da Alemanha unificada em plena ascensão econômica, do final do século XIX;

- Alfred Döblin (1993), recuperando a vida da classe operária e lúmpen da Berlim, capital da República de Weimar, no entre-guerras dos anos 20 deste século; e, finalmente,

- Irina Liebmann (1994), resgatando a vida da Berlim dividida pouco antes e logo depois da queda do Muro de Berlim, isto é, na última década (1985-94).

Assim procedendo, parto da tese de que a vida e cultura de uma cidade são cristalizadas em toda sua vivacidade e riqueza nas obras literárias, que contribuem para preservar a especificidade e singularidade de uma época, por vezes até melhor que documentos, reportagens, filmes, vídeos. Os bons romances conseguem abordar os diferentes planos da vida subjetiva e objetiva, reproduzir intuições e descrever cenários, resumir fatos e deter-se em detalhes, criar uma trama e recriar ambientes. Ao mesmo tempo em que fazem a radiografia da sociedade e a psicanálise de seus personagens, resgatam diferentes momentos históricos, preservados em sua unicidade e singularidade, no texto literário.

Nicolaus Sombart compara Berlim a Tróia. Após cada guerra Berlim teria renascido sobre os escombros da cidade anterior, dando-lhe uma nova fisionomia que nada ou pouco tem a ver com a camada arqueológica anterior ${ }^{4}$.

Essa tese, não capta a essência do que é e foi Berlim, como tentarei mostrar no decorrer da minha flânnerie literária.

O primeiro mapa de Berlin/Coeln, registrado como documento, datado de 1237.

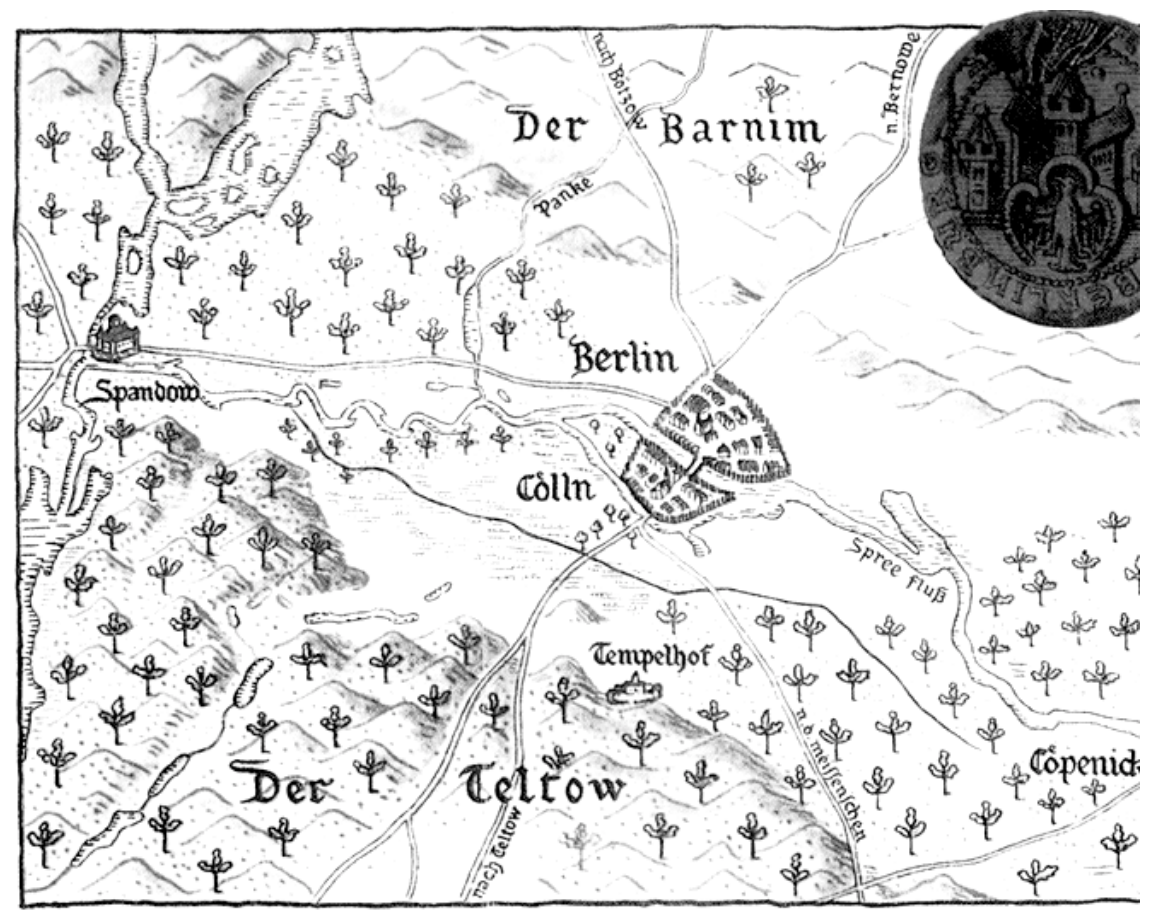




\section{A Berlim das obras literárias}

Pela limitação de espaço que se impõe a qualquer ensaio, vejome forçada a uma seleção mínima de autores berlinenses (ou residentes em Berlim), que refletem a "memória literária" da cidade.

Minha escolha recaiu em Theodor Fontane (1819-1898), Alfred Döblin (1878-1957) e Irina Liebmann (1943- ). Esses três autores recobrem em seus romances passados em Berlim aproximadamente 100 anos de "história" da cidade.

As épocas retratadas intercalam-se entre quatro Guerras: a Franco-prussiana (1870), a I Guerra Mundial (1914-1918), a II Guerra Mundial e, finalmente, a Guerra fria, todas deixando marcas profundas no tecido, na estrutura e na vida urbana berlinense.

Nenhum dos romances examinados se passa na guerra; os três situam-se, claramente, nos poucos "nichos" de paz que a cidade conheceu neste último século. Nenhum deles, lamentavelmente, está traduzido para o português, razão pela qual cito passagens mais longas dos textos analisados.

Fontane, natural de Neu-Ruppin, situada no noroeste da capital, a $60 \mathrm{Km}$ desta, passou a maior parte de sua vida em Berlim, onde trabalhou como farmacêutico. Em Frau Jenny Treibel e Der Stettin, dois dos seus romances de maturidade, Fontane dá uma visão da Berlim que se transforma de sede da aristocracia rural dos Junker em capital da burguesia industrial em franca ascensão. Fontane está para a cidade de Berlim como Lima Barreto está para o Rio de Janeiro.

Döblin, que eternizou a cidade em seu romance de sucesso mundial, Berlin Alexanderplatz ${ }^{5}$, foi médico e viveu, até sua emigração em 1933 (era de origem judaica), na parte oriental da cidade. Aqui fizera seus estudos secundários e universitários, aqui atendeu seus pacientes, via de regra operários, aqui encontrou o cenário para o seu grande romance no Alexanderplatz. Natural de Stettin, integrada por 40 anos na Alemanha Oriental, preferiu viver depois de 1945 na Alsácia, onde adquiriu a nacionalidade francesa, e onde morreu bastante pessimista e amargurado em 1957.

Liebmann, nasceu durante a II Guerra em Berlim, como filha de um comunista alemão e uma mãe russa, passando sua infância, adolescência e vida adulta em Berlim (Oriental). Filha de um alto funcionário do regime socialista, conheceu "mordomias" inesperadas em sua infância, como ser levada de carro oficial para a escola. Contudo, perdeu cedo tais privilégios: com a ascensão de Honecker, seu pai caiu em desgraça.

Liebmann estudou sinologia em Leipzig e vive hoje como intelectual e free-lancer em Schöneberg, bairro ocidental da velha e nova capital alemã.

Obviamente, poderia ter optado por outros autores para cobrir a "memória literária" dos últimos 100 anos de Berlim. Para o pri- 
meiro período dos Gründerjahre, emergem nomes como Gustav Freytag, Arnold Holz, Johannes Schlaf, Bruno Wille, entre outros (cf. Mc Farlane, 1987, pp. 105-119).

O nome de Bertold Brecht (cf. Völker, 1976) brota "naturalmente" para o período de Weimar e o pós-guerra, já que passara anos decisivos de sua vida, antes e depois da II Guerra em Berlim. Veio 1928 de Augsburg para Berlim, onde, juntamente com Helene Weigel (sua futura mulher) foi freqüentador do Romanisches Kaffee, no Kurfürstendamm. Depois de sua emigração durante o período nazista, que o levou para a Dinamarca, União Soviética, Estados Unidos e Suíça, voltou para Berlim Oriental (endereço: Chausseestrasse), onde veio a falecer. Está enterrado no cemitério, chamado dos "Idealistas", fazendo companhia a Hegel, Schelling, Schlegel e outros.

Mas curiosamente, as peças de Brecht não passam em Berlim, apesar de terem como cenários grandes cidades (Im Dickicht der Städte, Aufstieg und Fall der Stadt Mahagony, Die heilige Johanna der Schlachthöfe), via de regra americanas (cf. Brecht, 1957).

Outros nomes para a primeira metade do século XX em Berlim se impõem, Heinrich Mann, Gerhard Hauptmann, Arthur Schnitzler e tantos outros. Mas nenhum deles consegue, a meu ver, traduzir a vivência, os dramas e conflitos da grande metrópole alemã do entre-guerras, dilacerada entre progresso e miséria, comunismo e nazismo, riqueza e pobreza com a maestria de Döblin.

O destino de Franz Biberkopf, seu personagem central, o carregador de móveis preso por homicídio na prisão de Tegel e liberado depois de quatro anos, revela toda a grandeza e miséria da classe operária durante a República de Weimar. A decisão de ser honesto é inviabilizada pela estrutura urbana, pela sociedade de classes, pelas instituições totais como posto policial, prisão, hospital e hospício. Ela ainda é boicotada por seus pares, produtos e reflexos dessas mesmas condições de vida.

Franz Biberkopf será, apesar de livre e em sua essência honesto, um prisioneiro de seus condicionamentos de classe, um ladrão e gigolô por necessidade de sobrevivência; uma vítima da violência institucionalizada entre seus pares (o ambiente lúmpen em que circula) e em instituições de reclusão, planejadas para deter e disciplinar as classes subalternas? .

Döblin retrata os matadouros de Berlim da Eldenaer Strasse de uma forma que supera de longe a dramaticidade do Brecht da Santa Joana dos Matadouros. Neste capítulo, estabelece o paralelo da indústria da morte de gado com a indústria da morte do homem moderno. E sem querer, e sem saber (?), antecipa o Holocausto nazista com seus campos de concentração e seus campos de extermínio como Teresienstadt, Dachau, Auschwitz, e tantos outros ${ }^{8}$.

Também no caso da escolha de uma romancista contemporânea da Alemanha e de Berlim "Oriental", o leitor informado perguntará, por 
FREITAG, Barbara. Berlim: fronteiras imaginárias, fronteiras reais? Tempo Social; Rev. Sociol. USP, S. Paulo, 6(1-2): 127-145, 1994 (editado em jun. 1995).

que a escolha não recaiu em Christa Wolf ou outros autores de renome desta outra Alemanha?.

Sabemos hoje da vida privilegiada que levavam os intelectuais e escritores consagrados e oficialmente reconhecidos do regime socialista. Também sabemos das práticas de uma censura auto-imposta pelos próprios escritores (como C. Wolf), confirmada e radicalizada por cientistas, como o historiador americano Darnton (que as expôs em sua dramaticidade na reunião da ANPOCS em Caxambu em 1992) (Darnton, 1992). Por isso mesmo, preferi escolher uma autora da geração mais jovem, "acima de qualquer suspeita”, nascida em 1943, cujo sucesso literário é recentíssimo.

Como seu pai se havia incompatibilizado com o regime de Honecker no poder, a visão crítica do Estado e do regime socialista fez parte de sua infância e adolescência. $\mathrm{O}$ desejo de dar as costas a esse regime emergiu, assim, mais cedo e de forma mais autêntica que entre os outros autores.

Se tenho "minhas razões" em discutir os três autores citados, certamente haveria razões justas e irrefutáveis, para escolher outros. Há contudo um argumento central, que justifica minha escolha, e que aqui formulo sob forma de uma nova tese:

Os textos literários acima citados, convergem - como é fácil demonstrar - para uma constatação curiosa: a cidade dividida pelo "Muro da Vergonha”, o Muro de Berlim (1961-1989), já estava dividida antes de erigir-se o Muro, e continua dividida com a sua queda, depois da reunificação. É o que nos transmitem os textos dos três romances em questão.

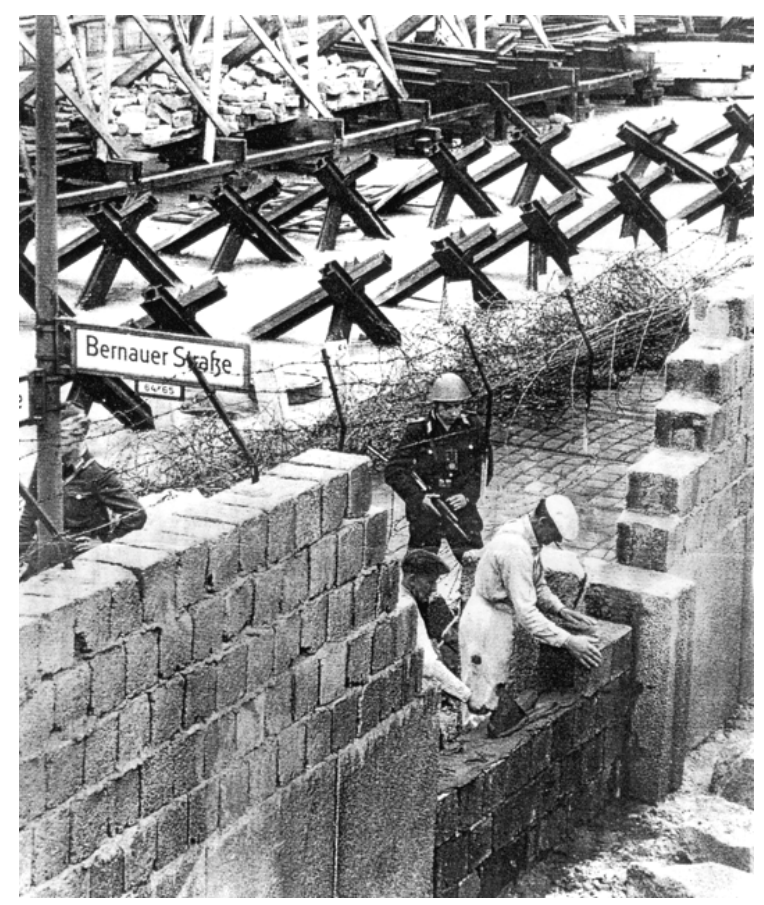

A construção do Muro de Berlim (o "Muro da Vergonha") pelo governo socialista alemão, em 1961. 
Acompanhando os personagens centrais dos romances de Fontane em suas andanças pela cidade de Berlim, como Jenny Treibel, uma nouveau riche cheia de si, autoritária e matriarca, percebe-se que ela, seus familiares e seus amigos somente se movimentam nos bairros "nobres", "aristocráticos", "tradicionais" da velha Berlim do Império Prussiano (Tiergarten, Dahlem, Wannsee) ou nos "novos bairros industriais" da alta burguesia da Berlim dos "fundadores", bairros que naquela época e até hoje, pertencem à Berlim ocidental ${ }^{10}$.

Em contrapartida, o leitor de Döblin, que se der ao trabalho de acompanhar os itinerários de Franz Biberkopf, de suas amantes e seus colegas "de copo e de cruz" pelas ruas (Rosenthalerstrasse) e praças (Alexanderplatz) da metrópole da República de Weimar, notará que ele se movimenta exclusivamente em Berlim oriental, em uma área da cidade reservada aos semi- e desempregados. Aqui a classe média dos funcionários públicos, a alta burguesia industrial e financeira ou até mesmo os intelectuais, jornalistas e escritores como o próprio Benjamin, Heinrich Mann, Bert Brecht, Helene Weigel, entre outros, não circulavam ${ }^{11}$.

Também a intelectualidade renomada de Berlim, que deu fama e notoriedade à Berlim da República de Weimar, preferia encontrar-se no Romanisches Kaffee, em Berlim ocidental, ao lado da igreja Kaiser Wilhelm Gedächtniskirche (ainda intacta naquela ocasião), área que depois de finda a II Guerra e dividida a cidade, transformou-se no "centro" da Berlim Ocidental.

Curiosamente, nem um e nem o outro grupo de pessoas, movimentam-se pelo Berlin-Mitte, centro imperial, sede e símbolo da Berlim Guilhermina, planejada e construída pelos grandes arquitetos e urbanistas, Knobelsdorf e Schinkel no século XIX.

Irina Liebmann, residente antes e depois da "guinada" no bairro de Berlim oriental de Pankow, relata em um texto auto-biográfico, suas angústias de cidadã "encarcerada" no assim chamado Arbeiter und Bauernstaat (o Estado dos trabalhadores e camponeses) de Ulbricht e Honecker. Só pensa em abandonar sua cidade, fugir para o outro lado do Muro ${ }^{12}$.

A autora, que relata, na terceira pessoa, sua vida na cidade cortada pelo Muro, acompanha como observadora a protagonista do romance. As ações e os pensamentos da "Liebmann", são relatados como se ela estivesse falando de "outra", uma Liebmann, alter-ego, alter-id. Essa Liebmann movimenta-se, 60 anos depois de Franz Bieberkopf, nos mesmos lugares que este: Rosenthalerstrasse, Friedrichstrasse, Hackescher Markt. No Café Praha encontra-se com seus amigos, amantes, visitantes ocasionais. Na Friedrichstrasse e na estação de trem (S-Bahn) de mesmo nome, locais oficiais de trânsito e aduana entre as duas Alemanhas, observa o vai vem dos raros visitantes de Berlim ocidental, e a longa fila daqueles berlinenses orientais que conseguiram, depois de anos de espera, um visto de saída, para deixarem atrás de si o socialismo real. 
FREITAG, Barbara. Berlim: fronteiras imaginárias, fronteiras reais? Tempo Social; Rev. Sociol. USP, S. Paulo, 6(1-2): 127-145, 1994 (editado em jun. 1995).

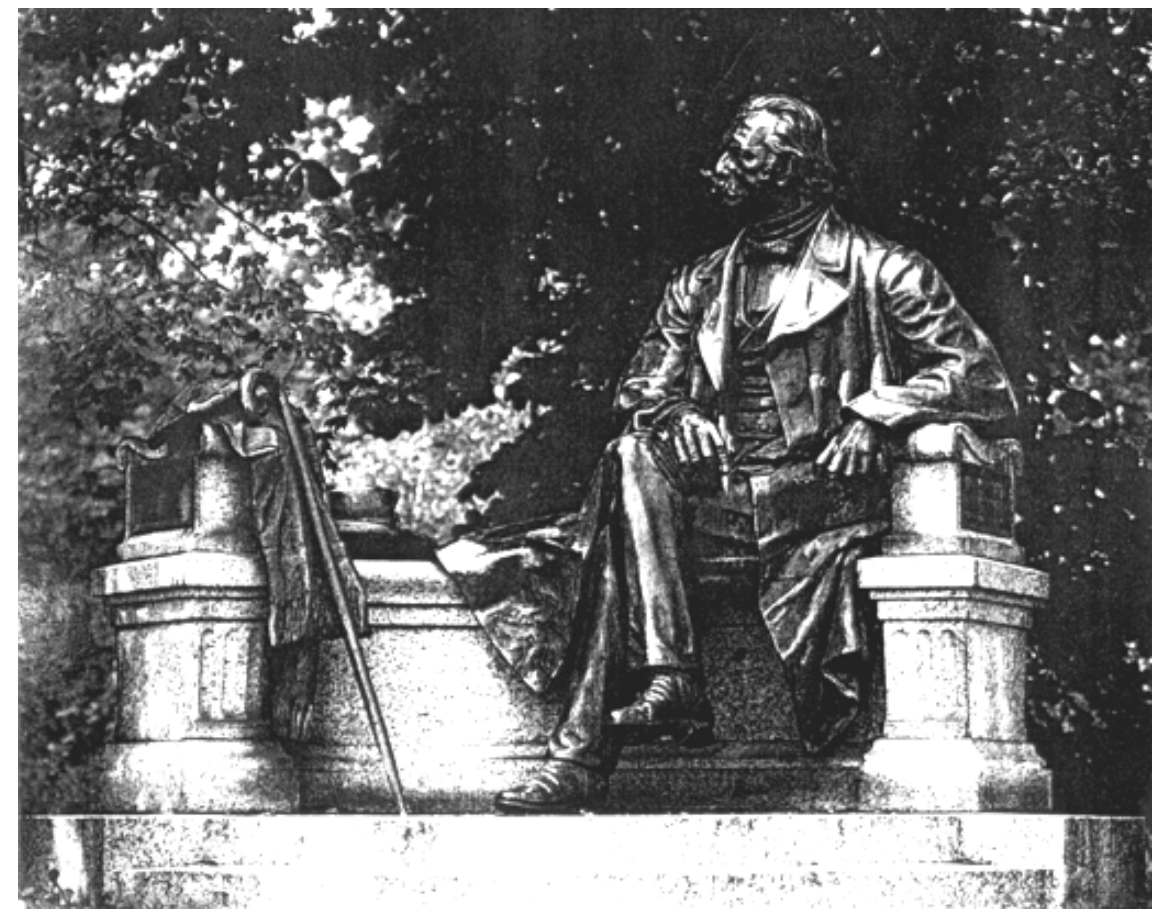

A Liebmann fará tudo para obter um passaporte que lhe garanta a liberdade no mundo Ocidental. Consegue-o um ano antes da queda do Muro. O carimbo diz: Reisende (Viajante), assegurando-lhe, se quiser, a volta a Pankow. E... poucos meses depois de ter saído, acontece o inexplicável: ela quer voltar para Pankow, seu bairro em Berlim Oriental. Nada consegue segurá-la na parte Ocidental de Berlim. A Kantstrasse, o Kurfürstendamm, a Gedächtniskirche, a estação da S-Bahn Zoo, tão simbólica para o visitante do mundo "livre", que visita a cidade "livre" protegida pelos americanos, ingleses e franceses ${ }^{13}$ parecem-lhe opressivos. Por isso mesmo, fará uso de sua condição de Reisende (viajante), e volta. A partir de então, será uma Pendlerin: qual pêndulo de um velho relógio, sente-se rejeitada pelos berlinenses ocidentais e atraída pelos orientais; tem o sentimento de estar "em casa" em seu apartamento de Pankow quando vem do Zoo, e dele se cansa depois do primeiro telefonema. Não pertencerá mais a nenhum lado. Para voltar a sentir-se bem em Berlim, terá que reinventar uma nova cidade, integrada, inteira.

Perguntei-me, ao ler ou reler os três romances acima citados, se o "enclausuramento", a "guetoização", a "limitação" dos personagens estudados que se movimentam segundo o princípio da exclusão ("ou/ ou") e não segundo o princípio da integração e coordenação ("e/e") concretizados em um lado "oriental" ou um lado "ocidental" da cidade era uma mera coincidência, um "acaso" ou se havia realmente duas cidades, mesmo antes do muro, que não se intercomunicavam, ou que meramente se tangiam?
Monumento em homenagem a Theodor Fontane em Neuruppin. 
Encontrei na história da cidade, a prova da sua "esquizofrenia urbana". Berlim sempre foi uma cidade dual, cindida, estruturada em duas, materialização de contradições aparentemente irreconciliáveis ${ }^{14}$.

Uma volta às origens históricas de Berlim revela que a cidade da "modernidade" da qual falei até agora, dos Gründerjahre (1870) à Queda do Muro (1989), em verdade se originou de dois pequenos vilarejos à beira do Rio Spree, do século XIII: Coelln, ocupando uma ilha central, formada por dois braços do rio, habitada originalmente por pescadores; e Berlin, do lado direito da Spree, formada por comerciantes.

Hoje (1994), tanto Coelln quanto o núcleo de Berlim, Nikolaiviertel, pertencem ao centro da cidade: Stadtmitte. Na primeira, os Hohenzollern construíram a sede de seu império, o castelo (das Berliner Schloss), derrubado no pós-guerra por Ulbricht. Saudosistas da Berlim imperial fazem hoje campanha para reconstruí-lo. Na segunda, a Berlim original, os comunistas erigiram, sobre os escombros do Alexanderplatz, tematizado por Döblin, a torre de televisão, de $365 \mathrm{~m}$. de altitude, der lange Alex ou Spargelturm (a torre do aspargo) na voz popular. Aqui também os socialistas reergueram o Rotes Rathaus, a sede da municipalidade, primeiramente construída no final do século XIX. Mas o "vermelho" (=rot) no nome não advém da convicção ideológica e sim da construção em tijolo vermelho aparente.

Historicamente, como se sabe, as duas cidades medievais, foram fundidas em uma, remanejadas e redivididas. Mas na cabeça dos seus habitantes a dualidade manteve-se através dos séculos.

Isto também é confirmado pelos críticos literários, como Walter Benjamin ou memorialistas, como o já citado Nicolaus Sombart. Em seus textos vemos confirmada a tese da divisão espacial. Berlim foi e é, no passado e no presente, na vivência de seus escritores e críticos, historiadores e comentadores, como no dia-a-dia de seus habitantes (Ossis e Wessis) uma cidade dividida. A polarização pode mudar de nome (leste e oeste, pobres e ricos, empresários e trabalhadores, comunistas e capitalistas, etc.) mas resiste ao tempo e à história.

Walter Benjamin descreve o seu bairro, Tiergarten, ao qual voltam as suas lembranças em várias passagens de sua obra (1990, p. 385$433)^{15}$. São dele as expressões de "enclausuramento" (Eingeschlossenheit) e "guetoização", em termos de uma segregação total entre ricos e pobres, empresários e trabalhadores. Sua infância de menino da abastada burguesia judaica, está salpicada de imagens de ruas, praças e parques que sempre pertenceram à área "burguesa" da cidade, quarteirão das embaixadas e da antiga aristocracia dos junkers, onde também se movimentavam, em décadas anteriores os descendentes do Senhor de Stechlin, o major e Junker Valdemor, do romance Der Stechlin de Theodor Fontane.

Nicolaus Sombart, o filho de Werner Sombart (1863-1941) autor do clássico Der moderne Kapitalismus (1902-1928) e Der Bourgeois 
FREITAG, Barbara. Berlim: fronteiras imaginárias, fronteiras reais? Tempo Social; Rev. Sociol. USP, S. Paulo, 6(1-2): 127-145, 1994 (editado em jun. 1995).

(1912), confirma em seu relato sobre os seus anos de infância e juventude em Berlim (1993) essa dualidade da capital da República de Weimar (Sombart, 1993) ${ }^{16}$.

Há também, como já chamei atenção em meu artigo "Duas cidades (Berlim e Brasília) entre a história e a razão"(1992), uma confirmação teórica para a dualidade, defendida por Levi-Strauss e seus adeptos estruturalistas. Segundo tais teóricos, a organização do espaço urbano exprime a lógica de uma cultura. Trata-se de uma lógica das oposições, de antagonismos que ajudam a delimitar a natureza da sociedade, as proibições das liberdades, as regras sociais das leis naturais, o espaço sagrado do profano. $\mathrm{O}$ espaço urbano materializa o que pode e o que não pode acontecer entre os membros de uma aldeia, tribo, comunidade, sociedade. A separação entre "sacerdotes", "reis", em suma, os "privilegiados", dos mortais comuns, profanos ("o povo", "a plebe", "as massas") se materializa nos espaços das modernas metrópoles, como nas primitivas aldeias bororo ou winibago (cf. Levi-Strauss, 1955, p. 106 e 1973, p. 377-420) ${ }^{17}$.

Mais recentemente, o sociólogo americano Sennett (1989) retomou essa oposição sob a forma do espaço "público" e "privado"18. Uma versão brasileira nos foi fornecida pelo antropólogo carioca Roberto da Matta em seu A Casa e a Rua (1991) ${ }^{19}$.

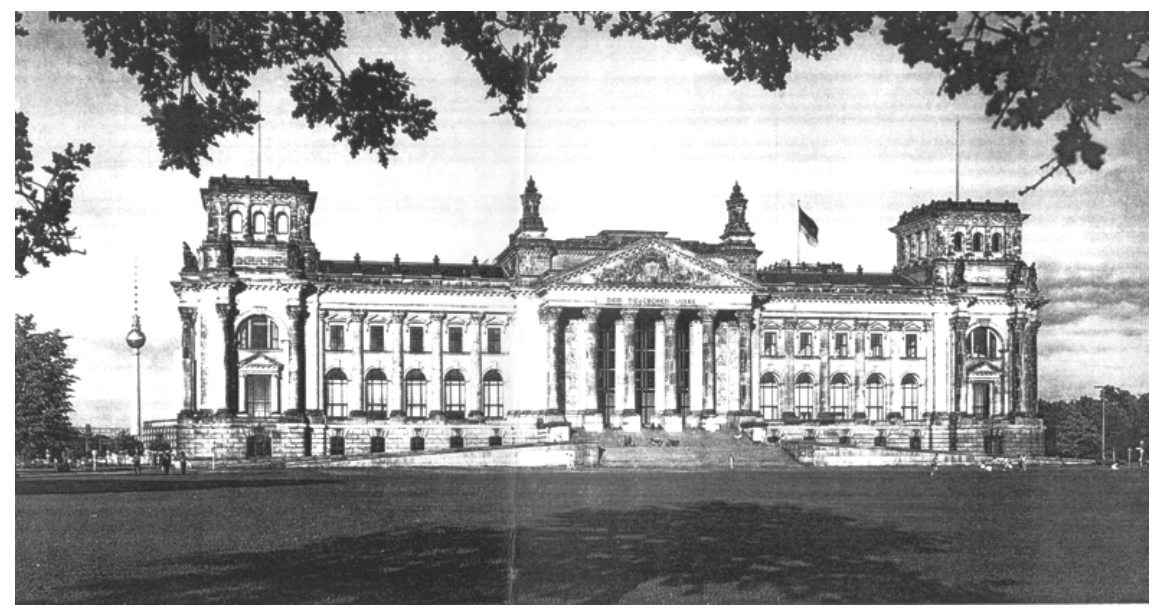

O Futuro Político de Berlim

Há cinco anos este "dado" histórico, que parecia estar aceito por todos, sofre um abalo "sísmico". O que já parecia ser natureza (o caráter dual da cidade) revela ser "histórico", "mutável", "transitório": Cai o Muro de Berlim, exatamente no ano em que se festejava o bicentenário da Revolução Francesa.

Com essa "queda" ou "guinada" (Wende, termo hoje oficialmente usado pelos alemães de ambos os lados) também estaria superada, suprimida a dualidade histórica e estrutural, evocada e confirmada na literatura clássica e recente?
O Reichstag, o Parlamento alemão, depois de 1945: uma ruína. Hoje reconstruído, segundo os planos originais do século XIX. 
FREITAG, Barbara. Berlim: fronteiras imaginárias, fronteiras reais? Tempo Social; Rev. Sociol. USP, S. Paulo, 6(1-2): 127-145, 1994 (editado em jun. 1995).

Procurarei responder a essa pergunta em duas etapas.

Num primeiro esforço, procurarei fazer um empréstimo aos três romancistas aqui examinados (Fontane, Döblin, Liebmann) para verificar se é possível extrair de seus romances alguma resposta satisfatória para o futuro político de Berlim.

Na segunda etapa, retornarei à tese defendida por Nicolaus Sombart: das múltiplas Berlins, sedimentadas em camadas arqueológicas, qual Tróia, fazendo emergir, sobre os escombros da cidade anterior uma cidade "nova", que rompeu totalmente com a "memória" e "tradição" das cidades anteriores.

Vejamos, primeiro, o que nos dizem os romancistas:

Fontane sempre foi visto como um autor conservador, no máximo liberal, que captara com sutileza ímpar e com uma leve nostalgia o declínio da aristocracia prussiana, relatando a morte do major Voldemar, em seu último romance, Der Stechlin. Ao mesmo tempo, capta com fina ironia a ocupação do espaço vazio por uma nova classe política e econômica: a burguesia industrial e financeira, em ascensão na Prússia, tematizada em Frau Jenny Treibel. Sua ironia e crítica sutil revelam seu distanciamento cético (e crítico) com relação às duas classes.

Fontane decididamente não é reacionário, o que também vale para os seus personagens. Mas qual a visão de futuro que tinha um autor que morreria no fin de sciècle (XIX)?

Poucos leitores e ouvintes saberão que Fontane participou, empolgado, nas lutas de rua e barricadas na Berlim de $1848^{20}$.

Barricadas de Berlim em 1848.
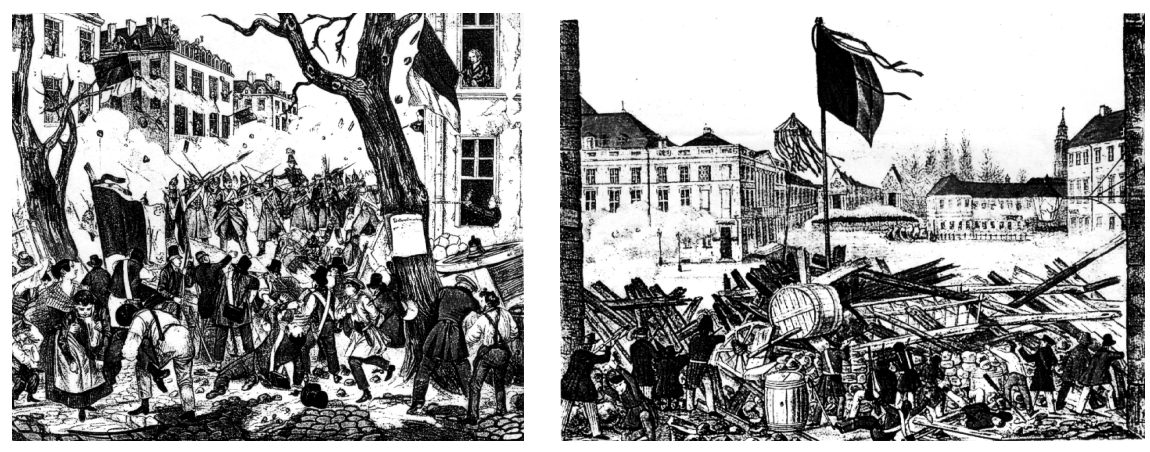

E poucos acreditarão que justamente ele (sem ser marxista ou revolucionário), partilhava com Marx a idéia de que a inovação para a sociedade alemã viria, em sua opinião, da classe operária ${ }^{21}$.

Curiosamente para a história de Berlim, a visão romântica de Fontane viria concretizar-se um século depois. É justamente na Berlim "operária", que se instaura o primeiro Estado socialista alemão, fazendo de Berlim Oriental a sede e capital do primeiro Arbeiter und Bauernstaat da Alemanha a partir de 1948. Cinqüenta e um anos mais tarde, esse Estado e essa "nova" sociedade ruiriam em suas bases materiais e sociais. 
O futuro político da Alemanha e de Berlim foi decidido neste Estado dos trabalhadores e camponeses. Foram os trabalhadores que em protesto ao regime autoritário do "socialismo real", optaram pelo capitalismo e não pelo socialismo; rejeitaram o "enclausuramento" em favor da liberdade; trocaram o autoritarismo pela democracia.

Se Fontane tinha uma visão romântica da atuação do proletariado como inovador da sociedade futura, que não transparece em suas figuras dos romances aqui citados, Döblin reflete um realismo - sem par em sua época - quanto às possibilidades e limites da classe operária como agentes da história.

Faz parte dos paradoxos da história: Fontane parece ter ficado com a razão, apesar de e talvez por ignorar de todo, a organização política e o estado de alma da classe operária de seu tempo. Em contrapartida, Döblin, conhecedor de Marx, enquanto intelectual, e do psiquismo do operário berlinense, enquanto médico, parece equivocar-se nas duas versões de encerramento do seu romance.

Assim, no primeiro "fim" de Franz Biberkopf, Döblin deixa morrê-lo no asilo psiquiátrico. Sua morte tem duas causas: a recusa de viver nas condições dadas e seu aniquilamento sistemático por parte dos médicos, psiquiatras, policiais e comparsas.

O futuro político da Berlim aqui enunciado simboliza a visão pessimista que tinha Döblin do futuro da cidade. As estruturas sociais do capitalismo são mais fortes. Berlim materializa e institucionaliza perfeitamente em seu espaço urbano a hegemonia do capital, da burguesia, do poder autoritário. Não há vez para o socialismo, a classe operária. O projeto de abertura democrática e de ruptura com a estrutura de classes já parecia estar abortado no final dos anos vinte do nosso século XX. A República de Weimar, em outras palavras, não trouxera a liberdade esperada e deixa vingar os canalhas, os "espertos", os "sabidos" na figura de ladrões como o Pims, Reinhold e os médicos psiquiatras que (mal) tratam Franz Biberkopf até a morte.

O segundo "final" encenado no romance - certamente o primeiro parecera a Döblin demasiado derrotista - faz ressuscitar o personagem central do romance. Franz Bieberkopf volta para as ruas de Berlim, mas apático, com a coluna vertebral quebrada. Não tem mais vontade própria, nem espírito de luta. Está mutilado, pois perdera seu braço direito no acidente provocado pelos ladrões que decidiram matá-lo. Este homem, representante de sua classe, não constitui mais nenhum risco para a sociedade vigente. Ele trabalhará como porteiro de um prédio comercial, no mesmo Alexanderplatz de sempre.

Nesta versão, Berlim voltou à sua rotina de antes. Nada mudou, tudo continuará como sempre: o trânsito passando, os bondes emitindo seus guinchos, os desempregados e as prostitutas batalhando pelo pão de cada dia. 
Döblin transmite duas versões pessimistas para o futuro de Berlim no final do seu romance Berlin Alexanderplatz que afortunadamente não se concretizaram da maneira como temia. Encontramos, contudo, no próprio romance, elementos para um diagnóstico do horror que viria a ser o regime nazista de Hitler na metáfora do matadouro, já citada, como em muitas outras passagens do livro. Em sua vida política e literária encontramos um ativista político que luta por uma Berlim que ainda está por se concretizar, alertando para os riscos de uma Berlim socialista, nos moldes do então partido Comunista do qual Döblin fora membro.

O Partido Comunista de sua época e seu sucessor, a SED (Sozialistische Einheitspartei Deutschlands) nunca lhe perdoariam seus "desvios políticos", seja nas versões do romance, seja em sua trajetória pessoal. Döblin tinha sido um socialista ativo em sua juventude, lutando contra as ameaças da direita, que já pressentia ao voltar dos campos de batalha da I Guerra para Berlim. Nesta ocasião, abandonou o partido cuja "Bonzenwirtschaft" (autoritarismo combinado a um burocratismo elitista) considerava insuportável e insustentável. Conclamou os alemães em seu manifesto Wissen und Verändern (Saber e Mudar) para um socialismo humano, liberado do marxismo, já em 1931! Essa posição política reflete-se em seu romance clássico Berlin Alexanderplatz não como a realidade vigente, mas como uma "utopia", discutida em Kneipen (bares) e Cafés.

Essa postura poderia gerar uma terceira versão final de seu romance: uma Berlim com futuro político. Tratar-se-ia de uma Berlim que sabe de seu passado e aceita as mudanças necessárias para evitar os desastres já vividos, conquistando as formas de uma cidade unida, livre, tolerante e humana.

E Irina Liebmann? A autora de sucesso recente com seu In Berlin termina seu romance com a pergunta que nos atordoa: Und nun, Liebmann, wie geht es weiter? ${ }^{22}$ (E agora, Liebmann, como isso continuará?). E na tentativa de buscar uma resposta, a autora fala na Berlim que agora está aberta e emenda: "quem quiser e não desembarcar agora" (do bonde que atravessa fronteiras) vê a cidade toda (ganz).

Como em português, a palavra ganz tem a dupla conotação de todo e de consertado (refeito). Mas die ganze Stadt (a cidade toda) poderia ainda ter uma terceira conotação: a de concertada, no sentido de harmonizada, acertada entre partes conflitantes. A autora sabe que isso exige um esforço de vontade. Nada será automático. Nada será dado de presente aos berlinenses. Para que a cidade volte a ser um todo, uma cidade sem buracos, lacunas, descosturada, recortada em dois ou mais pedaços, e sim uma cidade harmonizada, integrada, será necessária uma vontade política, um desejo da população de hoje de refazer a cidade para o futuro.

Não basta constatar que o Muro caiu, que as duas partes da cidade não estão mais separadas e inacessíveis para os de lá e de cá. Mas é 
FREITAG, Barbara. Berlim: fronteiras imaginárias, fronteiras reais? Tempo Social; Rev. Sociol. USP, S. Paulo, 6(1-2): 127-145, 1994 (editado em jun. 1995).

preciso querer que Berlim venha a ser novamente uma verdadeira cidade: inteira, consertada e concertada.

Sem conhecer Levi-Strauss, Sennett e Roberto da Matta, Liebmann estaria propondo a superação da dualidade? A ruptura com os antagonismos? A supressão da polaridades?

Até aqui a literatura nos deu o que podia dar: Uma promesse de bonheur (com o romantismo de Fontane); um quadro desolador, talvez hoje injustificado (com o realismo desesperado de Döblin) e um otimismo cético (com o realismo vivido de uma alemã que conheceu o socialismo real e sofre no capitalismo atual).

Passo, agora, ao segundo esforço de "prever o futuro de Berlim" a partir da tese defendida por Sombart, das camadas arqueológicas da cidade, que não se intercomunicariam.

Lembremos que na década de oitenta, Sombart falara em quatro cidades que se sobreporiam qual camadas arqueológicas:

(1) a Berlim guilhermina de Marinetti (1870-1918);

(2) a Berlim judaica de Döblin (1918-1933);

(3) a Berlim nazista de Ernst Jünger (1933-1945);

e, finalmente,

(4) a Berlim dividida em duas depois de 1945.

Como todos os escritores, intelectuais, políticos e industriais dos anos oitenta, também Sombart tinha se conformado com a cidade dividida, explicitando em seu texto não publicado, que talvez esse fosse o seu melhor e mais duradouro destino.

Também Nikolaus Sombart, o sociólogo e ensaísta, foi surpreendido pela queda do muro, razão pela qual o artigo ficou inédito.

Isto não impede que se explore a sua tese, da afinidade eletiva de Berlim com Tróia e sua diferença com Roma.

Enquanto nesta conviveriam formas históricas de várias épocas, séculos e milênios, Tróia seria o modelo da cidade permanentemente arra-

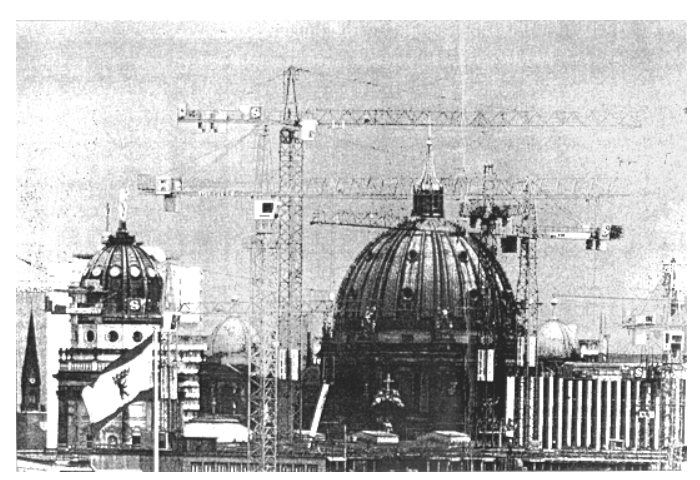
sada pela história e pelas guerras, o que lhe ditara seu destino: reconstruir-se, sempre nova, sobre os escombros da anterior.

Ora, isso significaria, como futuro para Berlim uma quinta edição da cidade: a Berlim, pósqueda do muro.

Berlim em reconstrução. 
FREITAG, Barbara. Berlim: fronteiras imaginárias, fronteiras reais? Tempo Social; Rev. Sociol. USP, S. Paulo, 6(1-2): 127-145, 1994 (editado em jun. 1995).

Para Sombart, essa cidade nada teria a ver com as anteriores. Seria outra cidade que nem Valdemor Stechlin, nem Frau Treibel, nem Franz Bieberkopf mas tampouco Irina Liebman e nem mesmo Nicolaus Sombart reconheceriam.

Seria a cidade ideal dos sonhos de qualquer urbanista e arquiteto, discípulo do Le Corbusier de 1925 ou de seus sucessores da Carta de Atenas: uma cidade por construir, da estaca zero, encima dos escombros de cidades anteriores que se revelaram "imprestáveis", "impróprias" para seus habitantes.

Por tudo que comentei aqui e em meu outro ensaio sobre Berlim (Freitag, 1992), anteriormente citado, não sou partidária da tese arqueológica de Nicolaus Sombart, pois justamente em Berlim convivem, visivelmente, todas as cinco supostas camadas arqueológicas. Isso nem sempre foi e está sendo o resultado de uma política urbana deliberada. Encontramos em toda a parte, tanto no espaço urbano quanto na memória e literatura de Berlim, como tentei mostrar neste ensaio, a presença de todos os períodos mais ou menos gloriosos da história da cidade.

Em lugar de uma observação conclusiva, termino minhas reflexões sobre o futuro de Berlim com algumas perguntas que me acompanham em minhas caminhadas pelas velhas e novas ruas e praças da cidade.

A Berlim do século XXI continuaria seguindo sua vocação dual, refletida na literatura urbana e na crítica literária ou teria chances de escapar a este "destino", reorganizando-se com "tolerância" (Fontane), com "humanismo" (Döblin) e como cidade "inteira" (Liebmann)? Seria absurdo imaginar para o século XXI uma Berlim não cindida e dilacerada por falsas oposições (materializadas no muro do século XX)) mas como cidade "plural", "múltipla", "integradora" dos contrários, "ponte” entre o Leste e Oeste, Norte e Sul, reunindo pobres e ricos, judeus e cristãos, em paz?

Recebido para publicação em fevereiro/1995

FREITAG, Barbara. Berlin: imaginary frontiers, real frontiers? Tempo Social; Rev. Sociol. USP, S. Paulo, 6(1-2): 127-145, 1994 (editado em jun. 1995).

\footnotetext{
UNITERIMS:

Imagery, real frontiers, imaginary frontiers, Berlin, Berlin wall.
}

ABSTRACT: In this article, the author tries to re-construct, through the novels of Theodor Fontane (1819-1899), Alfred Döblin (1878-1957), and Irina Liebmann (1943) the city landscape during three decisive periods of Berlin's history: (I) the years of the "Founders" (Gründerjahre), since 1870; (II) the years of the Weimar Republic, between the two World Wars, and, finally, (III) the twenty-eight years of the existence of the Berlin Wall. Cant these literary images of the past help us to forecast the shape of Berlin "after the Fall"? 


\section{Notas}

${ }^{1}$ Berlin, Sinfonie einer Grossstadt (1926), de Walter Ruttmann, é o mais famoso entre eles. Um outro é Berlin wie es war. Este filme de Leo de Laforgue da Reichshauptstadt (capital do império) foi realizado em 1938. Quando pronto, foi proibido por Goebbels, o Ministro de Propaganda de Hitler, pois já haviam começado os bombardeios sobre Berlim. Temendo reações negativas da população, devidas às destruições sistemáticas que Berlim sofreu nos últimos três anos da II ${ }^{a}$ Guerra, destruindo $80 \%$ do tecido e da substância urbana, o filme ficou engavetado. Reencontrado em 1950, foi restaurado e comentado pelo Prof. Friedrich Luft, com intenções pedagógicas: reeducar as novas gerações alemãs para a paz.

Outro filme, bem mais recente sobre Berlim, foi feito por Wim Wenders em 1987 (Himmel über Berlin, literalmente: O Céu sobre Berlim), que fez sucesso no Brasil sob o título Asas do desejo, retrata a Berlim Ocidental, beco sem saída, antes da queda do "Muro".

Der Schwarzfahrer, de Pepe Danquart, que recebeu o OSCAR de 1994 para filmes de curta metragem, foi filmado em Berlim (Oriental) em 1993 e tematiza o preconceito racial na Berlim reunificada.

${ }^{2}$ Há uma versão histórica de 1931, direção de Piel Jutzi, com Heinrich George, do romance clássico de Alfred Döblin, Berlin Alexanderplatz (1929), que tem como cenário a Berlim, capital da República de Weimar, anterior à tomada do poder pelos nazistas. Uma nova filmagem do mesmo romance foi realizada por Werner Fassbinder em 1978 para um seriado de televisão, que teve de reconstruir nos estúdios, os cenários da cidade na Spree. As imagens do filme de 1931 documentam uma "realidade urbana" que os bombardeios entre 1942 e 1945 enterrariam para sempre sob seus escombros.

3 Vide ainda seus textos autobiográficos (1987).

4 "Les quatres Berlins": Mythologie berlinoise (Nicolaus Sombart) - é um texto inédito, de oito páginas, escrito no início da década de 80, quando o filho de Werner Sombart resolve voltar para Berlim. Devo a indicação do texto (e uma cópia) a Bernard Genton, do Institut Français/ Berlin, a quem conheci em casa de N. Sombart, depois de concluída essa palestra. Sombart já se esquecera do texto. Nele fala de quatro Berlins: a de Marinetti, que termina em $1918 \mathrm{com}$ o final da primeira Guerra Mundial e a queda do Kaiser; a de Döblin, despreparada para dar o passo da sociedade fortemente hierarquizada para a sociedade aberta; a de Ernst Jünger, que prepara o advento de Hitler e o III Reich; e, finalmente a Berlim dividida em capitalista e socialista, depois de 1945. Curiosamente, Sombart atribui a essa quarta Berlim as maiores chances de sobrevivência. A Queda do Muro em 1989 parece ter inviabilizado a publicação do texto, ou melhor, da interpretação dada à quarta Berlim.

${ }^{5}$ O romance teve duas versões cinematográficas: a primeira, de 1931, dirigida por Piel Jutzi e a segunda, originalmente feita para uma mini-série de televisão (ARD) em 1978 de Werner Fassbinder (cfe. elucidado na nota 2).

${ }^{6}$ Die Drei-Groschen-Oper (a Ópera dos Três Vinténs), passa, como é sabido, em Londres.

${ }^{7}$ Franz Bieberkopf, no final do romance, sente-se perdido na cidade; ele nela circula sem rumo e sem um destino claro e, quando se dá conta, está diante dos muros da prisão em que esteve encarcerado, em Berlin Tegel: "Os bondes correm ao longo das ruas; eles seguem pela rua Schiller, por Pankow, pela rua Breite, pela praça Nollendorf, pela praça Uhland, pela estação Schmargendorf, pelo Grunewald; ai entro. Bom dia, eu me sento, eles podem me levar onde querem. E Franz começa a olhar a cidade como um cachorro que perdeu o rastro. Que cidade! Que cidade gigantesca. E que vida! Que vida ele já levou nela. Na estação de Stettin ele desce. E então percorre a rua dos Inválidos. Ali está o portão de Rosenthal. Confecções Fabisch. Ali fiquei apregoando minha mercadoria: grampos de gravata, no último Natal. Depois de Tegel ele pega o 41. E quando aparecem as paredes vermelhas, à esquerda, as paredes vermelhas, os pesados portões de ferro, Franz fica mais calmo. Isto é parte da minha vida e eu tenho que olhar para isso. Olhar.

Os muros estão ali, vermelhos, e a avenida segue ao longo deles; o 41 passa por eles; rua General-Pape, Reinickendorf Oeste, Tegel, a fábrica Borsig martela. E Franz Biberkopf pára diante dos muros, vai para o lado, onde está o botequim. E as casas vermelhas atrás dos muros começam a tremer e balançar e a inchar as bochechas. Há presos em todas as janelas. Batem a cabeça contra as barras, têm o cabelo raspado à altura de meio milímetro; eles têm um aspecto miserável, subnutrido, todos rostos cinzentos, com a barba por fazer, rolam os 
olhos e se lamentam. São culpados de assassinato, assalto, furto, falsificação, estupros, todos os artigos da lei; e se lamentam com seus rostos cinzentos, eles estão presos, os cinzentos; agora eles estrangularam Mieze” (Döblin, 1993, p. 349, tradução de Barbara Freitag e Sérgio Paulo Rouanet).

8 Para o leitor interessado recomendo a leitura da passagem entre as páginas 118 e 124, na edição citada. Aqui um pequeno recorte:

"Prédios administrativos amarelos, um obelisco para os soldados, vítimas da guerra. E à direita e à esquerda os longos prédios com seus telhados de vidro; trata-se das estrebarias, dos chiqueiros, salas de espera. Láfora um tabuleiro negro: Propriedade da Associação dos Matadouros de Berlim S. A.. Os galpões do gado bovino, os galpões do gado suíno, o matadouro, propriamente dito: o tribunal dos animais, o machado em punho, daqui você não me escapa vivo. Ruas calmas nas imediações: rua Strassmann. Liebig, Proskauer, parques cultivados em que as pessoas passeiam. Elas moram aconchegadas umas às outras, se uma delas adoece e tem dor de garganta, o médico vem correndo." (Döblin, 1993, p. 118, tradução de Barbara Freitag).

9 Uma boa seleção fornece a coletânea 19 Erzähler der DDR, que justamente se propos a apresentar a "nova geração de autores", da Alemanha socialista, depois de Bert Brecht, Arnold Zweig, Anna Seghers e outros. Entre os autores contam: Erich Neutsch, Werner Bräunig, Fritz Rudolf Fries e tantos outros.

10 “A vila dos Treibel estava situada num grande terreno com fundo muito amplo, que se estendia da rua Köpenick até o rio Spree. Antes somente havia aqui na proximidade imediata do rio, edifícios de fábricas, nos quais eram produzidos anualmente toneladas e toneladas de sais químicos, e mais tarde, quando a fábrica se expandiu quantidades igualmente elevadas de anil. Mas depois da Guerra de 1870, quando os bilhões começaram a afluir para o país, a mania de grandeza dos "fundadores" começou a contaminar até mesmo as cabeças mais sóbrias. Nesse momento, o empresário Treibel achou que sua residência, até então localizada na velha rua Jacob, apesar de ser atribuída ao arquiteto Gontard, e segundo alguns até mesmo a Knobelsdorff; não estava mais de acordo com a época e a sua posição social. Conseqüentemente, construiu no terreno de sua fábrica, uma vila no estilo da moda; com um pequeno jardim na frente e um parque nos fundos. Esta vila era um sobrado cujo piso superior, devido as suas janelas baixas, dava mais a impressão de um mezzanino que de um andar principal. Aqui Treibel morava há dezesseis anos e não compreendia como podia ter agüentado tanto tempo na velha rua Jacob, tão pouco aristocrática e tão desprovida de ar fresco, só por causa de um presumido arquiteto da época de Frederico, o Grande. Pelo menos esses sentimentos eram partilhados por sua mulher Jenny.

A proximidade da fábrica, quando o vento era desfavorável, trazia consigo todo tipo de efeitos desagradáveis. Mas o vento do Norte, que empurrava a fumaça, era sabidamente raro e, afinal, não era necessário fazer recepções sociais justamente quando esse vento soprava. Além disso, Treibel elevava cada vez mais alto, as chaminés da fábrica, com isso diminuindo cada vez mais o mal-estar.” (Fontane, 1979, p. 13, tradução de Barbara Freitag e Sérgio Paulo Rouanet).

${ }^{11}$ Döblin descreve essa praça, (20 anos depois totalmente destruída durante a Segunda Guerra Mundial) em sua vida e dinâmica durante os anos vinte: "Estão abrindo as ruas junto ao Alexanderplatz para a construção do Metrô. Caminha-se por cima de tábuas. Os bondes atravessam a praça e seguem a rua Alexander $e$ Münster em direção ao portão de Rosenthal. Nas ruas erguem-se prédios contra prédios. Estes estão emperrados de pessoas, do porão ao sótão. No térreo: lojas. Destilarias, restaurantes, comércio de frutas e verduras, produtos coloniais e especiarias, loja de carretos, pintura decorativa, confecção feminina, farinha e produtos farináceos, garagem de carros, corpo de bombeiros...” (1993, p. 105).

"Acima e atrás das lojas encontram-se apartamentos, por detrás ainda vêm pátios, prédios laterais, transversais, prédios de fundo, casebres em áreas verdes. A rua Linien, aqui encontra-se a casa, em que Franz Biberkopf se refugiou depois da cagada com o Lüders.” (p. 106)... "Franz Biberkopf, cuide-se! O que resultará desse lamaçal? Sempre deitado em seu quarto, somente bebendo e matutando, matutando! -

Isso não é da conta de ninguém. Se eu quiser matutar, matuto até amanhã e neste mesmo lugar. Ele come suas unhas, geme, rola a cabeça no travesseiro encharcado de suor, sopra pelo nariz. Fico deitado até depois de amanhã, se quiser. Se a velha pelo menos acendesse o fogão. Mas essa é preguiçosa, só pensa em si.

Gira a cabeça contra a parede, no chão vê um mingau, uma poça - vômito. Deve ter sido eu. O que uma pessoa não leva em seu estômago. Buh. Teias de aranha no canto cinzento, essas 
FREITAG, Barbara. Berlim: fronteiras imaginárias, fronteiras reais? Tempo Social; Rev. Sociol. USP, S. Paulo, 6(1-2): 127-145, 1994 (editado em jun. 1995).

não pegam as ratazanas. Quero beber água” (p. 110, tradução de Barbara Freitag).

Mais tarde, Jean Palmier escreve sobre a mesma praça:

"Poucos lugares em Berlim adquiriram a celebridade do Alexanderplatz. Coração da Berlim popular, essa praça não cessou de freqüentar as obras literárias: dos poemas expressionistas ao romance de Döblin, que a imortalizou. Em velhas fotografias distinguem-se suas lojas, os trilhos do bonde, formando uma curva gigantesca, alguns fiacres imóveis ao longo das calçadas. A Alexanderplatz de Döblin vive como um ser: muda de rosto como as estações, suspira com o ruído dos bondes e a beleza do romance.

A magia do livro está justamente em ter conseguido tornar tão vivos os personagens - o operário assassino Franz Bieberkopf, o crápula Reinhold, Mietze, Plums, os mendigos e as prostitutas - quanto a própria praça, as praças e as ruas que a cercam" (cf. Palmier, 1989, p. 31, tradução Barbara Freitag e Sérgio Paulo Rouanet).

12 "Fora daqui pensa a Liebmann, se você quiser dar no pé, os caminhos são conhecidos; e fica de novo diante da estante cheia de anotações e o monte de papel debaixo da mesa" (Liebmann, 1994, p. 27).

"Adeus bagulho.... Fotos como essas ela pode obter facilmente. Estão todas no monte. Queimar.

Fora daqui, pensa ela ao pisar na rua, ao subir escadas, ao descascar batatas; o que fazer, o que fazer? E só pode falar com a filha, que apoiando a cabeça no braço, come, xingando os professores de canalhas e porcos. Mas esse diálogo não leva muito longe” (p. 28).

${ }^{13}$ Já na parte ocidental de Berlim:

"A rua Kant assobia como um tubo de vento, cinza, a Liebmann vai para o Zoo. E aqui é o fim da linha. A estação é o Leste; a porta para o Leste.

Eu te conheço, diz a estação; eu também te conheço, pensa a Liebmann, pára sempre e procura com os olhos a câmara..."

"A Liebmann não voltou para lá, está parada na estação Zoo com o passaporte na bolsa. Percorre com o olhar a fachada, até o teto e as nuvens lá encima, e para baixo em direção da ponte do trem, o elevado construído sobra a rua. Embaixo, na sombra transeuntes, figuras com sobretudo, algumas viram sua cabeça para os homens sentados e deitados, à esquerda, à direita, perto das portas da estação, os caras estão inchados e mijados; eles olham os transeuntes debaixo; um deles está fingindo pensa a Liebmann: se é verdade que todos vêm do Leste, todos esses vagabundos, TRAIÇÃO.

... olha na bolsa, o passaporte ainda está dentro. De repente ela quer ir para o leste, no Zoo essa sensação the é bem clara. Na escadaria da estação (S-Bahn) todo filme agora de trás para frente, será possível, o vagão fedorento, as pessoas, os degraus que descem para o Kiosk da Intershop, para o hall de entrada, entrar na fila no balcão de controle de identidade, aqui ainda daria para voltar, fugir, aqui fede.... Uma hora, uma hora eu preciso para atravessar a fronteira, e vai" (Liebmann, 1994, p. 89 ss, tradução de Barbara Freitag e Sérgio Paulo Rouanet).

${ }^{14}$ Vide também Freitag (1992).

${ }^{15}$ Nestas anotações sobre sua infância em Berlim relata como passeia e vai às compras com sua mãe no bairro residencial do Tiergarten, o mesmo que já conhecemos através dos personagens de Fontane. No volume VI de suas obras reunidas encontramos outro fragmento, em que Benjamin se refere a Berlim, complementando seus depoimentos autobiográficos.

Aqui vide: Berliner Chronik (pp. 465-519). Benjamin fala aqui da transparências das imagens de uma cidade que se torna presente na memória do escritor: "Seja como for, ele ficava enclausurado neste bairro residencial dos ricos, sem saber de outros bairros. Os pobres para crianças de sua geração elas viviam no campo....

Sua primeira escapada para o mundo exótico da miséria foi - o que não é de surpreender - um ensaio escrito" (p. 471).

${ }^{16}$ Em seu capítulo Im alten Grunewald, N. Sombart descreve o bairro e a casa em que viviam os seus pais.

"O bairro residencial do Grunewald sempre foi especial... Aqui eu fui educado. Para mim, isso era Berlim. Raras vezes eu circulava em outros bairros, com exceção do Kurfürstendamm, do Tiergarten $e$ do centro histórico da cidade com as tílias, o castelo e a ilha dos museus. Mas chegar lá eram verdadeiras excursões, preparadas por longo estudo dos mapas" (p. 11).

${ }^{17}$ Num trabalho recente (Racine, 1993) essa polaridade do sagrado e do profano é retrabalhada de maneira magistral, a partir de um ponto de vista autenticamente religioso. 
FREITAG, Barbara. Berlim: fronteiras imaginárias, fronteiras reais? Tempo Social; Rev. Sociol. USP, S. Paulo, 6(1-2): 127-145, 1994 (editado em jun. 1995).

\footnotetext{
${ }^{18}$ Mais recentemente, do mesmo autor, vide (1990).

${ }^{19}$ o autor retoma neste livro recente um tema já tratado em seu livro de 1978 (Da Matta, 1983, p. 70-118).

${ }^{20}$ Vide Berger (1993, p. 85), cap. Märzrevolution. Aqui Berger relata um episódio em que Fontane, que neste ano tinha 28 anos, corria meio desnorteado e confuso pelas ruas alvoroçadas de Berlim, perguntando-se o que ele teria a ver com uma revolução. Enquanto meditava, aproximava-se um grupo de trabalhadores em coluna, ao qual se associou. Atravessaram o Alexanderplatz, em direção ao Teatro Real, o qual foi tomado de assalto. No seu interior, encontraram o que procuravam: armas (espadas, escopetas, espingardas...). Fontane apropriouse de uma delas tentando carregar a espingarda. Mas sua falta de experiência fez com que a entregasse, junto à barricada a um companheiro mais experiente, retirando-se para a sua casa. Entre seus quatro muros resolveu que não seria herói, mas voltou às ruas para pelo menos ser testemunha de mudanças sociais e históricas, únicas da cidade.

21 “... um mundo novo, melhor somente começará no quarto estado. (...) O que os trabalhadores pensam, falam, escrevem, efetivamente superou o pensamento, a fala e a escrita das velhas classes reinantes. Tudo é mais autêntico, mais verdadeiro, mais cheio de vida. Os trabalhadores atacam tudo de maneira original, e não somente tem objetivos novos, como os melhores caminhos para atingi-los" (citado por Swales, 1989, p. 77, retirado de uma carta de Fontane a James Morris de 22.02.96).

22 "Na esquina da Oranienburger, onde outrora ficava Keilich, é possível comprar carros, em frente, escombros atrás, de uma cerca. As calçadas na Oranienburger foram pavimentadas, a estação da S-Bahn que passa por baixo da rua, está aberta: mal iluminada, o teto baixo, a escrita nas paredes, gótica. Berlim está aberta. Quem quiser pode ir de Schönefeld até o Zoo [estação de S-Bahn e efetivamente o quarteirão central do Zoológico], quem não desembarcar, este vê Berlin toda” (p. 167, tradução de Barbara Freitag).
}

\section{REFERÊNCIASBIBLIOGRÁFICAS}

Benjamin, Walter. (1990) Berliner Kindheit um neunzehnhundert. In: . Gesammelte Schriften. Bd. VII. 1.

BERGER, Joachim. (1993) Berlin: Freiheitlich \& Rebellisch. Berlin, Goebel Verlag.

BRECHT, Bertold. (1957) Stücke. Berlin, Aufbau Verlag.

DA MatTA, Roberto. (1991) A casa e a rua. Espaço, cidadania, mulher e morte no Brasil. Rio de Janeiro, Guanabara Koogan.

. (1983) Carnavais, malandros e heróis: para uma sociologia do dilema brasileiro. $4^{\mathrm{a}}$ edição. Rio de Janeiro, Zahar.

DARnton, Robert. (1992) Dernière danse sur le mur. Berlin: 1989-1990. Paris, Editions Odile Jacob. Berlin journal: 1989-1990 (ed. americana).

DöBLIN, Alfred. (1993) Berlin Alexanderplatz (1929). 32ª edição. Hamburg, DTV.

FonTAnE, Theodor. (1979) Frau Jenny Treibel. Hamburg, DLV.

. (1987) Autobiographische Schriften (Meine Kinderjahre/Von zwanzig bis dreissig/Kriegsgefangen). Zurique, Manesse Verlag. . (1993) Der Stechlin (1899). Stuttgart, Reclam.

FreITAG, Barbara. (1992) Deux villes entre l'histoire et la raison (Brasília et Berlin). In: BANURI, Tariq, BAUdRILlard, Jean et alii. Un autre 
partage. Homme, Ville, Nature. Toulouse, Éditions Érès. Uma versão brasileira foi publicada no Rio como: Duas cidades entre a história e a razão. In: Homem, cidade, natureza (Número especial da Revista tempo brasileiro). Rio de Janeiro, Vol. 116.

Levi-Strauss, Claude.(1955) Tristes tropiques. Paris, Plon. . (1973) Race et histoire. In: Anthropologie structurale, vol. II. Paris, Plon.

Liebmann, Irina. (1994) In Berlin. Köln, Kiepenheuer und Witsch.

LinDNER, Rolf. (1990) Die Entdeckung der Stadtkultur. Soziologie aus der Erfahrung der Reportage. Frankfurt/Main, Suhrkamp Verlag.

Mc FARLANE, James. (1987) Berlin and the rise of modernism 1886-96. In: Bradbury, Macolm \& Mc Farlane, James (eds.). Modernism. A guide to european literature 1890-1930. London, Penguin Book.

Palmier, Jean-Michel. (1989) Retour à Berlin. Paris, Payot.

RACINE, Jean-Bernard. (1993) La ville entre Dieu et les hommes. Genève, Presses Bibliques Universitaires.

Sennett, Richard. (1989) O declínio do homem público. As tiranias da intimidade. São Paulo, Companhia das Letras. . (1990) The conscience of the eye. The design and social life of cities. New York, Alfred Knopf.

SOMBart, Nicolaus. (1993) Jugend in Berlin. 1933-1943. Ein Bericht. $1^{\text {a }}$ edição 1984. Frankfurt, Fischer Verlag (edição revista e ampliada).

Swales, Martin. (1989) Möglichkeiten und grenzen des fontaneschen realismus. In: ArNold, Heinz Ludwig (ed). Text + Kritik. Sonderband über Fontane. München, Text + Kritik.

Vários. (1974) 19 Erzähler der DDR. $1^{\text {a }}$ edição 1971. Frankfurt, FischerVerlag.

VÖLKER, Klaus. (1976) Bertolt Brecht. Eine Biographie. München/Wien, Hanser Verlag. 
